\title{
Canadian NCLEX-RN outcomes: A two-year cross-sectional exploratory study in Ontario
}

\author{
Nancy A. Sears ${ }^{* 1}$, Maha Othman ${ }^{1,2}$, Leah O'Neil ${ }^{1}$, Wilma M. Hopman ${ }^{3,4}$ \\ ${ }^{1}$ School of Baccalaureate Nursing, St Lawrence College, Kingston, Ontario, Canada \\ ${ }^{2}$ Department of Biomedical and Molecular Medicine, Faculty of Medicine, Queen's University, Kingston, Ontario, Canada \\ ${ }^{3}$ Clinical Research Institute, Kingston General Hospital, Kingston, Ontario, Canada \\ ${ }^{4}$ Department of Public Health Sciences, Queen's University, Kingston, Ontario, Canada
}

Received: March 31, 2017

DOI: $10.5430 /$ jnep.v7n10p36
Accepted: April 21, 2017

URL: https://doi.org/10.5430/jnep.v7n10p36

Online Published: May 3, 2017

Abstract

Background/Objective: In January 2015, 10 of 12 registered nurse regulators in Canada began using the National Council Licensure Exam for Registered Nursing (NCLEX-RN) as the entry-to-practice examination. We examine the NCLEX-RN performance of $\mathrm{BScN}$ graduates from three sites of one program across the first 2 years of its use. We aim to investigate the relationship between undergraduate academic performance and NCLEX-RN performance, and to determine predictors of success and/or failure on the exam.

Methods: A total of 215 graduates who wrote the 2015 or 2016 NCLEX-RN participated in the study. Course grades, final program percentage grade and GPAs, and students' time to complete the program are examined against pass/fail performance on the NCLEX-RN. Student's $t$ test and Chi Square tests are used for comparative analysis. Logistic regression identified the odds ratio and associated $95 \%$ confidence interval for each one-unit increase in GPAs as a predictor of success.

Results: Overall, 141 of 215 (66\%) graduates passed NCLEX-RN and 74 (34\%) failed, with no significant difference between the two years. Time to complete the program is significantly lower $(p=.002)$ and graduating GPA is significantly higher $(p<.001)$ among those who passed the NCLEX-RN compared to those who failed. With one exception, all course grades are significantly higher for students who passed, compared to those who failed. The odds of passing the NCLEX-RN increase by 10 (95\% CI 4.5 , 22.6) for each one-point increase in GPA. At a GPA of 4.0, zero failures on NCLEX-RN are observed.

Conclusions: To our knowledge, this is the first Canadian systematic institutional based study examining the relationship between NCLEX-RN performance and academic factors. The study concludes high academic performance remains a strong predictor for NCLEX-RN success. Future, preferably multicenter larger studies, could further the understanding of the performance on this exam in Canada and support practices enhancing students' success on the NCLEX-RN.

Key Words: NCLEX-RN, Nursing education, Canada, Student performance

\section{INTRODUCTION}

Individuals applying for registration as a registered nurse in Canada are required to meet entry-to-practice requirements established by the registered nurse regulator of the province or territory in which the applicant is seeking registration. All
12 of the provincial and territorial registered nurse regulators require applicants to have completed an approved Canadian university baccalaureate nursing education program, or if internationally educated, demonstrate proof of completion of a nursing education program the regulator deems equiva-

\footnotetext{
*Correspondence: Nancy A. Sears; Email: nsears@sl.on.ca; Address: School of Baccalaureate Nursing, St Lawrence College, Rm 44140, 100 Portsmouth, Ave, Kingston, ON, Canada.
} 
lent to an approved program. After successful completion of the educational program, additional entry-to-practice requirements must also be met, including successful performance on the nurse regulators' entry-to-practice nursing examination. Examinations playing a central role in decision-making determining who will and will not gain access to the practice of a profession through licensure, or as in the case of registered nurse status in Canada, through registration, are commonly referred to as 'high stakes' tests or examinations. ${ }^{[1]}$

In January 2015, registered nurse regulators in 10 of the 12 provinces and territories of Canada began using the National Council Licensure Exam for Registered Nursing (NCLEX$\mathrm{RN}$ ) as the entry-to-practice examination. Since individuals performance on the NCLEX-RN in Canada is a critical factor in nurse regulators' decisions to issue or not issue registration to a nursing applicant, the NCLEX-RN has been described as a 'high-stakes examination'. [2] In 2015, 9,048 graduates of baccalaureate nursing programs in Canada wrote the NCLEX-RN with 6,306 (69.7\%) passing on their first attempt. $^{[3]}$ At the time this paper was in development, the 2016 NCLEX-RN writing period was completed. National results for 2016 are expected to be available in 2017.

The NCLEX-RN poses questions within eight content areas: Management of care (17\%-23\% of the exam); Safety and infection control (9\%-15\%); Health promotion and maintenance (8\%-12\%); Psychosocial integrity (6\%-12\%); Basic care and comfort (6\%-12\%); Pharmacological and parenteral therapies (12\%-18\%); Reduction of risk potential (9\%-15\%); and Physiological adaptation (11\%-17\%). ${ }^{[4]}$ Exam writers must successfully 'pass' each content area in order to 'pass' the exam. Since 1994, the NCLEX-RN has employed computer adaptive testing using item testing theory (as opposed to classical testing theory likely used by most, possibly all, baccalaureate nursing programs in Canada) to gauge whether a writer passes or fails the exam. The candidate ability estimate is the measure of the individual's nursing knowledge, abilities, and skills resulting from the candidate's answer to each question, using item testing theory. ${ }^{[4]} \mathrm{A}$ logit score of 0.00 is the cut-off point the National Council of State Boards of Nursing has established as representing the minimum ability for safe practice by entry-level nurses. A logit is a statistical measurement unit reporting, for the NCLEX-RN, the relative differences between candidate ability estimates and question difficulties. Normal distribution of logit scale scores falls within 3.0 to minus 3.0 logits although the logit scale ranges from positive to negative infinity.

A recent review of literature published between 1984 and 2015 reports what is known about relationships between NCLEX-RN performance and undergraduate nursing pro-

Published by Sciedu Press gram performance. ${ }^{[5]}$ The review found higher grade point averages in nursing programs are significantly associated with passing the NCLEX-RN. ${ }^{[6-14]}$ One study in the review did not find a significant correlation between nursing program GPAs and successful performance on the NCLEX$\mathrm{RN} .{ }^{[15]}$ At a more granular level, there is evidence that student performance in some courses within nursing programs is predictive of NCLEX-RN success. While course names and content vary between educational institutions and across years, available literature suggests grades achieved in nursing program courses focused on theoretical nursing foundations, anatomy, pathophysiology, adult health, mental health, maternal child nursing and paediatric nursing are predictive of NCLEX-RN performance. ${ }^{[9,16,17]}$ The one study that did not find a significant correlation between nursing program GPAs and successful performance on the NCLEX-RN also did not find significant correlations between NCLEX-RN pass/fail performance and nursing program course grades. ${ }^{[15]}$ One study did not limit itself to nursing program courses and found achievement of "C" or higher grades in anatomy, physiology, microbiology, psychology, sociology and lifespan development was significantly associated with passing the NCLEX-RN. ${ }^{[17]}$ This evidence is generated from studies predominately originating in the USA. With no history of NCLEX-RN use in Canada before 2015, no evidence from the Canadian context is available.

The NCLEX-RN is accepted by the Canadian Council of Registered Nurse Regulators as a valid assessment of the knowledge, abilities and skills Canadian registered nurses require in their first year of practice. ${ }^{[3]}$ A 2013 practice analysis validated the NCLEX-RN test plan for use within Canada. ${ }^{[18]}$ In 2014, a study comparing current registered nurse practice in Canada with the 2013 practice analysis confirmed the NCLEX-RN was applicable and could support registration decisions in the jurisdictions poised to introduce this entry-to-practice exam in $2015,{ }^{[19]}$ although this judgment has been called into question by Salfi and Carbol. ${ }^{[2]}$

The available literature related to factors predictive of NCLEX-RN performance is limited to data from jurisdictions using the NCLEX-RN prior to 2015, notably most jurisdictions in the United States of America. With the introduction of the NCLEX-RN across 10 Canadian provincial and territorial jurisdictions, both a need and an opportunity for research related to Canadian nursing students and NCLEX-RN performance naturally presents. The current study aims to investigate relationships between Canadian students' performance on the NCLEX-RN in the early years of its administration in Canada and their undergraduate academic performance, and to identify related predictors of success/failure on the NCLEX-RN. This investigation is based on a one institution, 
3 site, 2-year pilot study. Long-term goals for the study are to inform teaching practices, and enhance Canadian students' capacity and preparedness for NCLEX-RN success.

\section{MethodS}

\subsection{Ethical considerations and consent}

The Research Ethics Boards of both St Lawrence College (SLC) and Laurentian University approved the study. All participants provided consent to the release of their academic history including their undergraduate grades in all courses of the program, as well as their final, aggregated program grade (e.g., overall percentage; overall grade point average). Participants also agreed to the use of their NCLEX-RN results in the study.

\subsection{Data collection}

The study was conducted at St. Lawrence College; Ontario, Canada. SLC's four-year (eight semesters) BScN program has three academic sites (Kingston, Brockville and Cornwall), and is one of five collaborative $\mathrm{BScN}$ program sites led by Laurentian University, Sudbury, Ontario. All students predicted to graduate in 2015 and 2016 were invited to participate. No substantive program changes in the form of course additions or deletions differentiated program delivery between these cohorts. Invitations were made via class visits by the researchers, as well as through electronic announcements via the sites' on-line communication and learning support system (Blackboard) and mass emails to all students.

The following data were extracted from SLC records for each participant: percentage grades in all 27 mandatory courses in the program across years one through four; final program grade (percent score); and the number of years participants spent in the program until successful completion of the program and graduation. Percentage final scores were converted to alphabetic and GPA grades (see Table 1). The program generally requires a minimum of eight semesters over four years of study. There is no standard part-time program. Some students fast-track by completing one semester during the third-year summer vacation period, completing the 8 semesters of the program in 3.5 years. Students requiring longer than the standard 4 years, to a maximum of 7 years, to complete the program have one or more of the following circumstances: course failure and repeat course participation; health issues requiring temporary withdrawal from the program; and/or health issues requiring reduced academic course load during one or more academic semesters. Students who fail a course are permitted one repeat attempt of the course. In cases of course failure followed by repeat participation, only the course marks for the second course attempt were available. To protect student health privacy, ethical considerations did not permit dissection of 'length of time in program' data by reason for extended time in the program. Capturing length of time in the program provided an opportunity to determine if collectively circumstances that contribute to extended time in the program, independent of the final program percent grade or GPA, are associated with performance on the NCLEX-RN.

Table 1. St Lawrence College's grading system

\begin{tabular}{lll}
\hline $\begin{array}{l}\text { Equivalent } \\
\text { Percentages }\end{array}$ & $\begin{array}{l}\text { Grade Points } \\
\text { (GPA) }\end{array}$ & $\begin{array}{l}\text { Alphabetical } \\
\text { Grades }\end{array}$ \\
\hline $90-100$ & 4.00 & $\mathrm{~A}^{+}$ \\
$85-89$ & 3.90 & $\mathrm{~A}$ \\
$80-84$ & 3.70 & $\mathrm{~A}-$ \\
$77-79$ & 3.30 & $\mathrm{~B}^{+}$ \\
$73-76$ & 3.00 & $\mathrm{~B}$ \\
$70-72$ & 2.70 & $\mathrm{~B}-$ \\
$67-69$ & 2.30 & $\mathrm{C}+$ \\
$63-66$ & 2.00 & $\mathrm{C}$ \\
$60 *-62$ & 1.70 & $\mathrm{C}-$ \\
$57-59$ & 1.30 & $\mathrm{D}+$ \\
$53-56$ & 1.00 & $\mathrm{D}$ \\
$50-52$ & 0.70 & $\mathrm{D}-$ \\
$0-49$ & 0.00 & $\mathrm{~F}$ \\
\hline
\end{tabular}

* $60 \%$ is the minimum grade for passing a course or the BScN program

As groundwork for the study, all 27 courses were mapped against the eight content categories of the NCLEX-RN according to an in-house scoring system based on both students' and faculty's understanding of the courses' content and the NCLEX-RN categories.

Nursing registration applicants in Ontario may write the NCLEX-RN more than once to attain a 'pass' status. ${ }^{[20-22]}$ Applicants who fail the NCLEX-RN must wait 45 days before reattempting the exam. ${ }^{[20]}$ Only participants' firsttime writing results were included in the study. NCLEX-RN results were gathered through participants' voluntary submission of their NCLEX-RN results to the researchers and through examination of participants' registration information on the provincial (Ontario) nurse regulator's web-site. The regulatory body's NCLEX-RN performance notice for each writer takes the form of either a notification of a 'pass' status without any details about the individual's performance on any of the NCLEX-RN eight content areas, or the form of a 'fail' status with limited information (above passing standard; near but below passing standard; below passing standard) about the individual's performance on each of the NCLEX-RN eight content areas. Participant submission of NCLEX-RN results included a copy of the regulatory body's notice of NCLEX-RN results, and/or participants' self-reports of their 
NCLEX-RN pass/fail status, generally including information about the number of questions written before the NCLEX$\mathrm{RN}$ generated the pass/fail result, and an estimate of the time taken to write the exam. A minimum number of 75 questions is used to determine NCLEX-RN pass vs. fail performance; the maximum number of questions is 265 . Maximum allowable writing time is six hours. ${ }^{[20]}$

To validate self-reported NCLEX-RN results and to impute non-self-reported NCLEX-RN results from the provincial nurse regulator's web-site, the following interpretation scale was used:

- General, unrestricted registration as a RN within 45 days of eligibility to write the NCLEX-RN = NCLEXRN first-write pass;

- Conversion of temporary registration as a $\mathrm{RN}$ to general, unrestricted registration as a RN = NCLEX-RN first-write pass. (RN applicants in Ontario may be granted temporary RN status for up to 6 months without writing the NCLEX-RN; failure of the NCLEXRN during this period results in an immediate revocation of the RN status); and
- Conversion of temporary registration as a $\mathrm{RN}$ to revocation of temporary registration as a $\mathrm{RN}=$ NCLEX$\mathrm{RN}$ first-write fail.

\subsection{Understanding the contribution of undergraduate courses to the NCLEX-RN}

To understand perceptions about intersections between each SLC-BScN course and the NCLEX-RN content areas, we mapped all 27 mandatory courses to the eight content categories identified the NCLEX-RN, ${ }^{[4]}$ particularly since the performance of the students in each of these categories constitute the detailed results in the case of exam failure. To complete this mapping, $\mathrm{BScN}$ faculty who teach the course on one or more academic sites and a sample of students who had completed all of the program courses were asked to rank the course vs. NCLEX-RN content relationship as being: strongly-linked, semi-linked, or not-linked. Strong linkages are assigned a score of 2, semi-linkages are assigned a score of 1 and no-linkages courses are assigned a score of 0 . The scores for each course are aggregated across multiple raters. The highest possible score is 16 and the lowest is 0 . Examples of the mapping scores are provided in Table 2.

Table 2. Examples of course mappings to NCLEX-RN content categories

\begin{tabular}{|c|c|c|c|c|c|c|c|c|c|c|}
\hline & $\begin{array}{l}\text { NCLEX-RN Content Areas } \\
\text { Courses }\end{array}$ & $\begin{array}{l}\text { Physiolo- } \\
\text { gical } \\
\text { adaptation }\end{array}$ & $\begin{array}{l}\text { Manage- } \\
\text { ment of } \\
\text { care }\end{array}$ & $\begin{array}{l}\text { Safety \& } \\
\text { Infection } \\
\text { control }\end{array}$ & $\begin{array}{l}\text { Health } \\
\text { promotion } \\
\text { \& } \\
\text { Main- } \\
\text { tenance }\end{array}$ & $\begin{array}{l}\text { Psycho- } \\
\text { social } \\
\text { integrity }\end{array}$ & $\begin{array}{l}\text { Basic } \\
\text { Care \& } \\
\text { comfort }\end{array}$ & $\begin{array}{l}\text { Pharmacolo- } \\
\text { gical \& } \\
\text { parenteral } \\
\text { therapies }\end{array}$ & $\begin{array}{l}\text { Reduction } \\
\text { of risk } \\
\text { potential }\end{array}$ & Score \\
\hline \multirow{3}{*}{ Year 1} & $\begin{array}{l}\text { LUSL } 1004 \\
\text { Nursing Praxis and Professional } \\
\text { Caring I }\end{array}$ & strong & strong & strong & strong & strong & strong & none & semi & 13 \\
\hline & $\begin{array}{l}\text { LUSL } 1056 \\
\text { Professional Growth I }\end{array}$ & none & none & none & none & none & none & none & none & 0 \\
\hline & $\begin{array}{l}\text { LUSL } 2105 \\
\text { Human Anatomy \& Physiology }\end{array}$ & strong & none & none & semi & none & none & semi & semi & 5 \\
\hline \multirow{4}{*}{ Year 2} & $\begin{array}{l}\text { LUSL } 2084 \text { (Pharmacology) } \\
\text { Nursing Praxis \&Professional } \\
\text { Caring III }\end{array}$ & strong & strong & strong & strong & strong & strong & strong & strong & 16 \\
\hline & $\begin{array}{l}\text { LUSL } 2220 \\
\text { Clinical Chemistry }\end{array}$ & semi & semi & semi & semi & none & semi & semi & none & 6 \\
\hline & $\begin{array}{l}\text { LUSL } 2144 \\
\text { Nursing Praxis \&Professional } \\
\text { Caring IV }\end{array}$ & semi & strong & strong & strong & strong & semi & strong & semi & 13 \\
\hline & $\begin{array}{l}\text { LUSL } 2107 \text { (Pathophysiology) } \\
\text { Health and Healing III }\end{array}$ & strong & semi & semi & semi & semi & semi & semi & semi & 9 \\
\hline \multirow{3}{*}{ Year 3} & $\begin{array}{l}\text { LUSL } 3084 \\
\text { Nursing Praxis \&Professional } \\
\text { Caring V }\end{array}$ & strong & strong & strong & strong & strong & strong & strong & strong & 16 \\
\hline & $\begin{array}{l}\text { LUSL } 3406 \\
\text { Nursing Inquiry and Praxis I }\end{array}$ & none & none & none & none & none & none & none & none & 0 \\
\hline & $\begin{array}{l}\text { LUSL } 3066 \\
\text { Professional Growth IV }\end{array}$ & none & semi & none & none & semi & none & none & none & 2 \\
\hline \multirow{3}{*}{ Year 4} & $\begin{array}{l}\text { LUSL } 4056 \\
\text { Professional Growth VI }\end{array}$ & semi & semi & none & semi & semi & semi & none & semi & 6 \\
\hline & $\begin{array}{l}\text { LUSL } 4416 \\
\text { Nursing Inquiry and Praxis III }\end{array}$ & none & none & none & none & none & none & none & none & 0 \\
\hline & $\begin{array}{l}\text { LUSL } 4094 \\
\text { Nursing Praxis and Professional } \\
\text { Caring VIII }\end{array}$ & strong & strong & strong & semi & semi & strong & strong & semi & 13 \\
\hline
\end{tabular}




\subsection{Statistical analysis}

Using SPSS version 24, data are initially analyzed descriptively, including frequencies and percentages for success and failure rate in each year, and means and standard deviations for GPAs, course grades, and time to complete the program. Student's $t$ test and Chi Square tests are used for comparative analysis of percentages of success and failures in total within each year, undergraduate course grades, GPAs and time to complete the program in relation to NCLEX-RN success. Logistic regression analysis is performed to identify the odds ratio and associated $95 \%$ confidence interval for each one-unit increase in GPAs as a predictor of success. The 8 NCLEX-RN failure reports received from participants are also examined. The performance of participants achieving below, near or above the performance standard is described.

\section{Results}

In total, across the two years there were 345 eligible students, of which 215 (62.3\%) participated. The total number of eligible students for the 2015 study year is 163 , of which 87 (53.4\%) participated; The total number of eligible students for the 2016 study year is 182, of which 128 (70.3\%) participated. Overall, 141 passed their first-write of the NCLEX$\mathrm{RN}$ and 74 failed. As shown in Table 3, the rate of participant success in NCLEX-RN is $69 \%$ and $63 \%$ in the first two years of its administration respectively with an overall success rate of $66 \%$. There is no significant difference between the two years. The rate of NCLEX-RN graduate first-write success (the sampling frame) is $62.2 \%$ and $79.3 \%$ in $2015^{[21]}$ and $2016^{[22]}$ respectively, indicating the participant sample is skewed somewhat towards the pass sub-group in 2015 and the fail sub-group in 2016.

Table 3. NCLEX-RN outcomes per year and combined

\begin{tabular}{|c|c|c|c|c|c|c|}
\hline & & & Fail & Pass & Total & $p$ value \\
\hline \multirow{4}{*}{ Year } & \multirow{2}{*}{2015} & Number & 27 & 60 & 87 & \multirow{6}{*}{.389} \\
\hline & & $\%$ within year & $31 \%$ & $69 \%$ & $100 \%$ & \\
\hline & \multirow{2}{*}{2016} & Number & 47 & 81 & 128 & \\
\hline & & \% within year & $37 \%$ & $63 \%$ & $100 \%$ & \\
\hline \multirow{2}{*}{ Total } & & Number & 74 & 141 & 215 & \\
\hline & & \% overall & $34 \%$ & $66 \%$ & $100 \%$ & \\
\hline
\end{tabular}

Table 4 shows the relationship between the number of years participants spent in the $\mathrm{BScN}$ program until graduation, and their final grade (percent mark) in the $\mathrm{BScN}$ program. Length of time in the $\mathrm{BScN}$ program (minimum length 3.5 years) is significantly longer $(p=.002)$ for participants who failed the NCLEX-RN. Final program grades (percentages) are significantly higher $(p<.001)$ among those who passed NCLEX-RN. This is further confirmed by the significant, negative correlation between the final grade and the time spent in the program $(r=-.363, p<.001)$.

Table 4. Relationship between the number of years participants needed to complete program and the final program grade and the NCLEX-RN results combined for the two years

\begin{tabular}{|c|c|c|c|}
\hline $\begin{array}{l}\text { NCLEX-RN } \\
\text { result }\end{array}$ & $\mathbf{n}$ & $\begin{array}{l}\text { Years in program* } \\
\text { Mean } \pm \text { SD }\end{array}$ & $p$ value \\
\hline Fail & 74 & $4.24 \pm 0.7$ & \multirow{4}{*}{.002} \\
\hline \multirow[t]{3}{*}{ Pass } & 141 & $4.00 \pm 0.4$ & \\
\hline & & Final program grade & \\
\hline & & Mean \pm SD & \\
\hline Fail & 74 & $75 \pm 4$ & \multirow{2}{*}{$<.001$} \\
\hline Pass & 141 & $79 \pm 5$ & \\
\hline
\end{tabular}

There is no significant difference in either length of time to complete the program or final program grade when the information is compared between the two years $(2015,2016)$. Mean values for length are 4.07 and 4.09 years respectively $(p=.74)$. For final program grade, the values are almost identical at $77.6 \%$ and $77.4 \%(p=.81)$.

Based on the limited data with respect to the number of questions completed on the NCLEX-RN (54 participants provided this information; 4 NCLEX-RN failures and 50 NCLEX-RN passes), those who passed have a significantly lower ( $p=$ .005 ) number of questions (mean $101 \pm 56$ with a minimum of 75 questions) as compared to those who failed (189 \pm 89$)$, and again there is no significant difference between the two years.

Table 5 demonstrates the relationships between $\mathrm{BScN}$ courses and NCLEX-RN performance. Mean grades range from 70\%-80\% across participants with NCLEX-RN failures and from $75 \%-89 \%$ across NCLEX-RN passes. With one exception (LUSL1007 Health and Healing I, $p=.125$ ), all course mean grades are significantly higher in students who passed, compared to those who failed the NCLEX-RN.

Faculty and student perceptions of the relevancy of courses to NCLEX-RN content areas (see Table 2) are not completely consistent with the statistically significant relationships between course performance and NCLEX-RN performance (see Table 5). This suggests faculty and student perceptions of relevancy of courses to NCLEX-RN content areas may be unreliable or, for courses perceived to be unrelated to NCLEX-RN content but statistically significantly related to passing the NCLEX-RN, there may be some factor other than the relevancy of the course to NCLEX-RN content areas associated with performance on the NCLEX-RN. 
Table 5. Undergraduate course grades in relation to NCLEX-RN performance

\begin{tabular}{|c|c|c|c|c|}
\hline & $\begin{array}{l}\text { NCLEX-RN } \\
\text { Pass Fail }\end{array}$ & $\begin{array}{l}\text { Course grade } \\
\text { Mean }\end{array}$ & Std. Deviation & $p$ value \\
\hline LUSL 1004 & Fail & 73.4 & 6.0 & \multirow{2}{*}{$<.001$} \\
\hline Nursing Praxis and Professional Caring I & Pass & 77.6 & 6.5 & \\
\hline LUSL 1056 & Fail & 72.4 & 6.5 & \multirow{2}{*}{$<.001$} \\
\hline Professional Growth I & Pass & 76.5 & 7.5 & \\
\hline LUSL 1206 & Fail & 78.5 & 8.0 & \multirow{2}{*}{$<.001$} \\
\hline Relational Practice I & Pass & 82.9 & 8.1 & \\
\hline LUSL 2105 & Fail & 69.8 & 7.4 & \multirow{2}{*}{$<.001$} \\
\hline Human Anatomy and Physiology & Pass & 75.7 & 9.9 & \\
\hline LUSL 1007 & Fail & 80.1 & 8.3 & \multirow{2}{*}{.125} \\
\hline Health and Healing I & Pass & 82.1 & 8.5 & \\
\hline LUSL 1094 & Fail & 73.3 & 5.8 & \multirow{2}{*}{$<.001$} \\
\hline Nursing Praxis and Professional Caring II & Pass & 77.6 & 6.7 & \\
\hline LUSL 1207 & Fail & 78.0 & 6.5 & \multirow{2}{*}{.009} \\
\hline Relational Practice II & Pass & 81.1 & 8.5 & \\
\hline LUSL 2084 & Fail & 71.3 & 5.5 & \multirow{2}{*}{$<.001$} \\
\hline Nursing Praxis \&Professional Caring III (Pharmacology) & Pass & 77.2 & 6.2 & \\
\hline LUSL 2006 & Fail & 74.4 & 6.2 & \multirow{2}{*}{$<.001$} \\
\hline Health and Healing II (Maternal/Paediatric) & Pass & 78.8 & 6.9 & \\
\hline LUSL 2036 & Fail & 73.5 & 6.8 & \multirow{2}{*}{$<.001$} \\
\hline Microbiology for the Health Sciences & Pass & 78.2 & 8.5 & \\
\hline LUSL 2220 & Fail & 68.5 & 7.3 & \multirow{2}{*}{$<.001$} \\
\hline Clinical Chemistry & Pass & 75.4 & 9.9 & \\
\hline LUSL 2144 & Fail & 70.0 & 6.1 & \multirow{2}{*}{$<.001$} \\
\hline Nursing Praxis \&Professional Caring IV & Pass & 76.9 & 6.9 & \\
\hline LUSL 2057 & Fail & 72.8 & 5.6 & \multirow{2}{*}{$<.001$} \\
\hline Professional Growth II (Ethics) & Pass & 77.6 & 6.5 & \\
\hline LUSL 2107 & Fail & 66.7 & 5.9 & \multirow{2}{*}{$<.001$} \\
\hline Health and Healing III (Pathophysiology) & Pass & 72.7 & 8.4 & \\
\hline LUSL 3005 & Fail & 72.3 & 5.9 & \multirow{2}{*}{$<.001$} \\
\hline Health and Healing IV & Pass & 76.7 & 6.2 & \\
\hline LUSL 3084 & Fail & 69.3 & 7.4 & \multirow{2}{*}{$<.001$} \\
\hline Nursing Praxis \&Professional Caring V & Pass & 75.2 & 7.2 & \\
\hline LUSL 3056 & Fail & 77.5 & 6.4 & \multirow{2}{*}{.001} \\
\hline Professional Growth III & Pass & 81.0 & 7.2 & \\
\hline LUSL 3406 & Fail & 78.0 & 6.6 & \multirow{2}{*}{$<.001$} \\
\hline Nursing Inquiry and Praxis I & Pass & 81.6 & 6.9 & \\
\hline LUSL 3206 & Fail & 80.4 & 6.8 & \multirow{2}{*}{.001} \\
\hline Relational Practice III & Pass & 83.6 & 6.1 & \\
\hline LUSL 3066 & Fail & 75.1 & 7.8 & $<.001$ \\
\hline Professional Growth IV & Pass & 79.3 & 7.6 & $<.001$ \\
\hline LUSL 3094 & Fail & 76.3 & 6.2 & $<0001$ \\
\hline Nursing Praxis and Professional Caring VI & Pass & 79.9 & 6.4 & $<.001$ \\
\hline LUSL 3416 & Fail & 72.2 & 7.8 & $<001$ \\
\hline Nursing Inquiry and Praxis II & Pass & 77.8 & 8.4 & $<.001$ \\
\hline LUSL 4056 & Fail & 86.6 & 5.6 & 002 \\
\hline Professional Growth VI & Pass & 89.3 & 6.1 & .002 \\
\hline LUSL 4084 & Fail & 68.6 & 5.5 & $<001$ \\
\hline Nursing Praxis and Professional Caring VII & Pass & 75.3 & 6.1 & $<.001$ \\
\hline LUSL 4206 & Fail & 82.4 & 6.1 & $<001$ \\
\hline Relational Practice IV & Pass & 86.4 & 7.0 & $<.001$ \\
\hline LUSL 4416 & Fail & 79.8 & 10.1 & 001 \\
\hline Nursing Inquiry and Praxis III & Pass & 84.4 & 9.0 & .001 \\
\hline LUSL 4057 & Fail & 79.0 & 9.9 & 012 \\
\hline Professional Growth V & Pass & 82.9 & 10.5 & .012 \\
\hline
\end{tabular}


Participants' final percentage grade were converted to numeric Grade Point Averages (GPA) and a logistic regression model was run to determine if GPA as a categorical variable representing overall academic performance in the program is a predictor for NCLEX-RN success. The association between GPA and pass/failure rates is significant $(p<.001)$ (see Figure 1). The odds of passing increased by $10.0(95 \%$ CI 4.5, 22.6, $p$.001) for each one-point increase in GPA. A multivariable model including year and length in program in addition to GPA indicated that neither year (OR $0.72,95 \%$ CI $0.36,1.36, p=.308$ ) nor length in program (OR $0.78,95 \%$ CI $0.42,1.43, p=.416$ ) contribute significantly to the model. At a GPA of 4.0 there are zero failures on the exam. This result indicates GPA is a significant predictor for performance on the NCLEX-RN.

To assess the level of failure on the NCLEX-RN, the detailed failure reports submitted by 8 out of the 74 failing students over the two years are examined. As shown in Figure 2, 75\%-
$80 \%$ of the participants who failed the NCLEX-RN score below but near the performance standard in the majority of NCLEX-RN categories. Between 13\%-38\% of these participants score below performance standard in one or more categories.

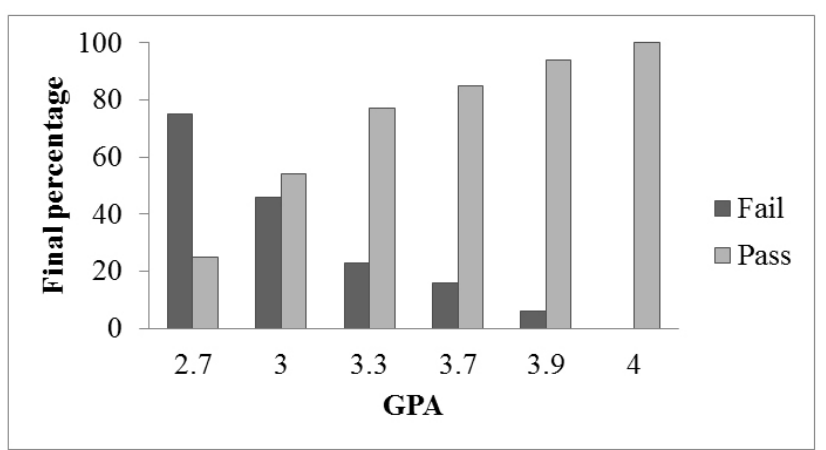

Figure 1. The relationship of academic grades as final percentages \& GPA with NCLEX-RN pass/fail performance

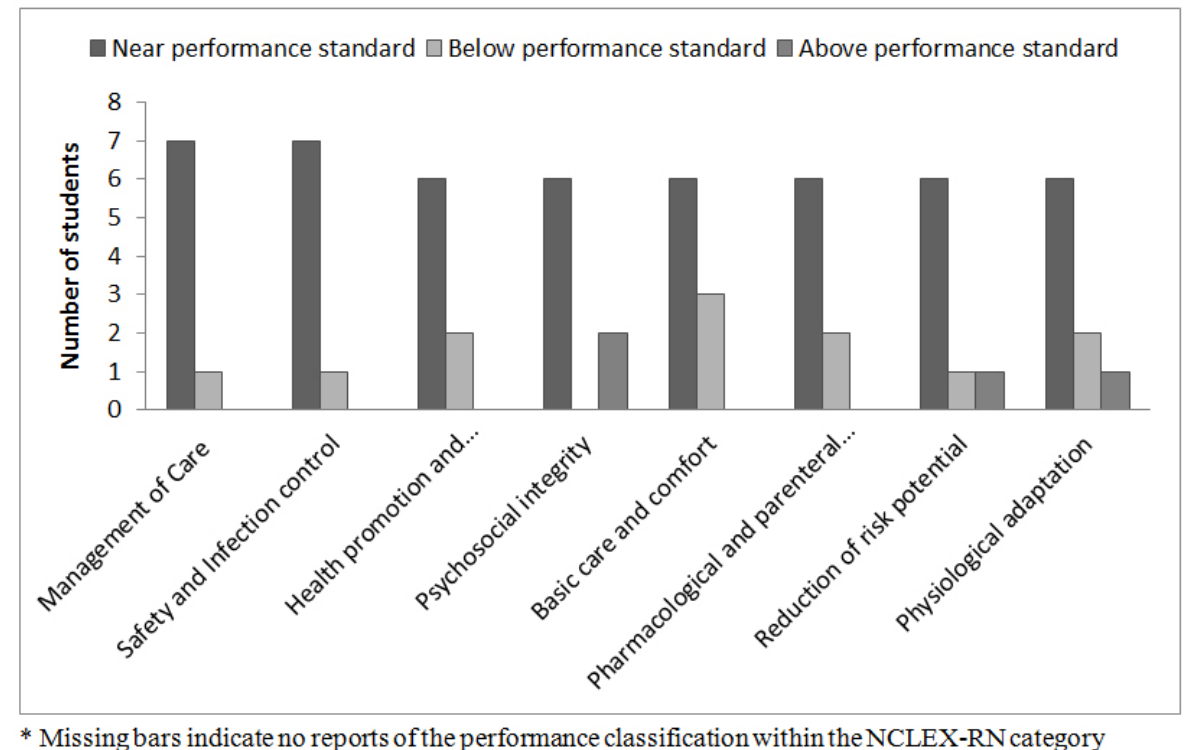

Figure 2. Evaluation of a sample of students' failure based on the different 8 NCLEX-RN categories*

\section{DiscuSSION AND CONCLUSION}

In January 2015, Canada began using the NCLEX-RN as the entry-to-practice examination for registered nurses. As with any new examination system, evaluating the outcomes is critically important not only to assess the applicability, suitability of and perceptivity about this entry-to-practice examination in a new environment but more importantly to support students' preparedness and success. This study adds to the evidence by expanding the examination of the relationships between undergraduate academic performance and NCLEX-RN performance, and determining predictors of success and/or failure on the exam, to the Canadian context.

The current exploratory study, based on graduates from three sites of one academic institution, evaluates the outcomes of first-write attempts of the NCLEX-RN in the first two years $(2105,2016)$ of its administration in Canada. The study demonstrates an overall participant success rate of $66 \%$ with no significant difference between the two years. The length of time for program completion is significantly lower (generally at the fast-tracked 3.5 years and standard 4 years duration) for those who pass the NCLEX-RN compared to those who fail, suggesting students who require longer than 
the standard 4 years to complete the program are at higher risk of failing the NCLEX-RN. Ethical considerations regarding student health privacy precluded a deeper examination of the relationships between reasons for extended enrolment in the program and NCLEX-RN performance. Final program percentage grades as a continuous variable, and GPA as a categorical variable, are significantly higher among those who passed the NCLEX-RN compared to those who failed. Based on the available limited data, those who pass, complete a significantly lower number of questions on the NCLEX$\mathrm{RN}$ as compared to those who fail. The mean course grades for all 27 mandatory undergraduate courses in the program range from $70 \%$ to $80 \%$ across participants with NCLEXRN failures and from 75\%-89\% across NCLEX-RN passers. Except for one course (LUSL1007 Health and Healing I), course grades are significantly higher in students who pass compared to those who fail the NCLEX-RN.

Based on this study, both the percentage final program grade and GPA are significantly associated with success on the NCLEX-RN. This is in agreement with most studies in literature $^{[6-14]}$ suggesting in Canada, as in the USA, academic factors are critical as predictors of success on this exam. The odds of passing increased by 10.0 for each one-point increase in GPA. A GPA of 4.0 was associated with zero failures on the exam. This result indicates GPA is a critical predictor for success on the NCLEX-RN.

The rates of NCLEX-RN success vary by academic institution across Canada. ${ }^{[3]}$ For both years, the first-write success rates at the academic institution studied is at the mean of all Ontario academic institutions whose graduates attempted the NCLEX-RN. ${ }^{[21,22]}$ The study site rate of NCLEX-RN success is also at the mean for the 2015 national (pan-Canada) results. ${ }^{[3]}$ The national 2016 data were not available at the time this paper was written. This suggests with caution, the results of this study may be somewhat generalizable to other Ontario and Canadian academic institutions. The methodology through which the data were gathered and analyzed should be replicable across BScN academic institutions across Canada.

In the literature, some controversy exists as to whether the performance in the various theoretical nursing courses can predict success on NCLEX-RN. ${ }^{[9,15-17]}$ In our study, a careful analysis of the 27 undergraduate courses of this BScN program shows, except for one course, there are significantly higher course grades in those who pass the NCLEX-RN compared to those who fail. In addition to what is reported in literature where theoretical nursing foundations, anatomy, pathophysiology, adult health, mental health, maternal child nursing and paediatric nursing course grades are related to success, in our study, for all BScN undergraduate courses except one, course grades are significantly associated to NCLEX-RN success or failure. This suggests there may some other factor, possibly individuals' innate academic acumen as demonstrated by a high GPA, in combination with knowledge available through the $\mathrm{BScN}$ curriculum, is germane to NCLEX-RN success. It is important to emphasize though, in the current shortage of Canadian literature and considering variations of courses' names and content across the various $\mathrm{BScN}$ programs in the province and nationally, these results need to be interpreted with caution. More structured and longer-term analyses are required to dissect the specific contribution of each undergraduate course to NCLEX-RN outcomes.

This study generates limited data with respect to NCLEXRN failure details. Since the study investigators did not have access to all failure reports, we relied on the information received from participants consenting to communicate this information. The analysis of the 8 NCLEX-RN failure reports show the majority of students who failed the NCLEXRN scored below but near the passing performance standard, with the poorest performance in the management of care, and the safety and infection control NCLEX-RN categories. There is currently limited literature with respect to specific analysis of NCLEX-RN failures. Further investigations examining factors predictive of NCLEX-RN failure, and factors predictive of NCLEX-RN category scores below the passing standard, are needed.

Undoubtedly, all Canadian baccalaureate nursing academic institutions aim to enhance student competency and promote the rate of success on the newly adopted NCLEX-RN. However, a much more challenging question is what can be done to promote this success. Annual assessment of the NCLEX$\mathrm{RN}$ outcomes using ongoing and evolving methods would help to address this knowledge gap. This assessment should also be evaluated in the context of current curricula, and teaching and delivery methods, as well as the content of courses. It would be useful to continuously examine and evaluate the NCLEX-RN questions and outcomes. A recent qualitative study conducted at two $\mathrm{BScN}$ programs within Ontario ${ }^{[23]}$ indicate perceptions of the first experiences of study participants with NCLEX implementation in Canada are less than positive despite the mean pass rate of $69.7 \%$ reported for the first year. The outcomes of this study should be re-examined as graduates of Canadian baccalaureate nursing programs develop more experience with this examination.

To our knowledge the current study is the first to examine institutional based NCLEX-RN outcomes and related predictors of success. The study concludes high academic 
performance remains a strong predictor for success. Currently, only few Canadian studies have reported on the Canadian NCLEX-RN experience ${ }^{[2,23]}$ Future studies from other Canadian academic institutions, preferably multicenter larger studies, are recommended. Large, multi-program, multi-site studies would allow greater generalizability of results and would allow more in-depth investigation into some issues such as differences in relationships between performance on the NCLEX-RN by cause of extended time to complete undergraduate programs. These studies are expected to further the understanding of the applicability and outcomes of this exam in Canada and are likely to support new practices to enhance students' NCLEX-RN success within the Canadian arena.

\section{ACKNOWLEDGEMENTS}

As co-principal investigators, M Othman and N Sears have contributed equally to the manuscript and would like to acknowledge St Lawrence College's applied research department for funding this project. We also acknowledge SLC's Registrar Rick Hunt, SLC's Record Lead Theresa Armstrong, and SLC's Senior Systems Analyst Malcolm Smith for great assistance in extracting data from student records. Additionally, we acknowledge all SLC BScN faculty and students who contributed to the mapping analysis and Dr. Mae Squires, Associate Dean of the School of Baccalaureate Nursing at SLC for facilitating all stages of the study including the funding.

\section{Conflicts of InTERest Disclosure}

The authors declare that there is no conflict of interest.

\section{REFERENCES}

[1] Sackett PR, Schmitt N, Ellingson JE, et al. High-Stakes Testing in Employment, Credentialing, and Higher Education Prospects in a Post-Affirmative-Action World. Am Psychologist. 2001; 56(4): 302318. https://doi.org/10.1037/0003-066X.56.4.302

[2] Salfi J, Barbol B. The Applicability of the NCLEX-RN to the Canadian Testing Population: A Review of Regulatory Body Evidence. Int J Nurs Educ Scholarsh. 2017; 14(1). https ://doi .org/10.1 515/ijnes-2016-0078

[3] Canadian Council of Registered Nurse Regulators. NCLEXRN 2015: Canadian Results. [Internet]. Beaverton (ON). 2016 Mar 31 [cited 2016 June 22]. Available from: http://www.ccrnr.ca/assets/2015-ccrnr-report-f inal-for-release-31-mar-2016.pdf

[4] National Council of State Boards of Nursing. Setting the NCLEX Passing Standards. [Internet]. Chicago (IL). [cited 2016 June 22]. Available from: https://www.ncsbn.org/2630.htm\#3455

[5] Sears NA, Othman M, Mahoney K. Examining the relationships between NCLEX-RN performance and nursing student factors, including undergraduate nursing program performance: A systematic review. J Nurs Educ Pract. 2015; 5(11): 10-15. https://doi.org/ 10.5430/jnep.v5n11p10

[6] Romeo EM. The Predictive Ability of Critical Thinking, Nursing G PA, and SAT Scores on First-Time NCLEX-RN Performance. Nurs Educ Perspect. 2013; 34(4): 248-253. http://dx.doi .org/10.54 $80 / 1536-5026-34.4 .248$

[7] Haas R, Nugent K, Rule R. The use of discriminant function analysis to predict student success on the NCLEX-RN. J Nurs Educ. 2004; 43(10): 440-446. PMid: 17152303

[8] Simon EB, McGinniss SP, Krauss BJ. Predictor Variables for NCLEX-RN Readiness Exam Performance. Nurs Educ Perspect. 2013; 34(1): 18-24. http://dx.doi.org/10.5480/1536-502 6-34.1.18

[9] Daley LK, Kirkpatrick BL, Frazier SK, et al. Predictors of NCLEX$\mathrm{RN}$ success in a baccalaureate nursing program as a foundation for remediation. J Nurs Educ. 2003; 42(9): 390-398. PMid:13677554

[10] Arathuzik D, Aber C. Factors associated with National Council Licensure Examination: registered nurse success. J Prof Nurs.
1998; 14(2): 119-126. http://dx.doi.org/10.1016/S8755-7 223(98) 80040-9

[11] Sayles S, Shelton D, Powell H. Predictors of success in nursing education. ABNF Journal. 2003; 14(6): 116-120. PMid:14969016

[12] Tipton P, Pulliam M, Beckworth C, et al. Predictors of associate degree nursing students' success students. South Online J Nurs Res. 2008; 8(1).

[13] Lavandera R, Whalen DM, Perkel LK, et al. Value-Added of HESI Exam as a Predictor of Timely First-Time RN Licensure. Int J Nurs Educ Scholarsh. 2011; 8(1): 1-12. http://dx.doi.org/10.2202 /1548-923X. 2152

[14] Giddens J, Gloeckner G. The relationship of critical thinking to performance on the NCLEX-RN. J Nurs Educ. 2005; 44(2): 85-89. PMid: 15719716

[15] Uyehara J, Magnussen L, Itano J, et al. Facilitating program and NCLEX-RN success in a generic BSN program. Nurs. Forum. 2007; 42(1): 31-38. PMid:17257393 http://dx.doi.org/10.1111/j $.1744-6198.2007 .00063 . x$

[16] McGahee TW, Gramling L, Reid TF. NCLEX-RNR success: are there predictors. South Online J Nurs Res. 2010; 10(4): 208-221.

[17] Alexander J, Brophy G. A five-year study of graduates' performance on NCLEX-RN. J Nurs Educ. 1997; 36(9): 443-445. PMid:9362029

[18] National Council of State Boards of Nursing. Research Brief Volume 60: 2013 Canadian RN Practice Analysis: Applicability of the 2013 NCLEX-RN Test Plan to the Canadian Testing Population. [Internet]. Chicago (IL). 2014 May. [cited 2016 June 22]. Available from: https://www.ncsbn.org/14_Canadian_Practice_Ana lysis_vol60.pdf

[19] National Council of State Boards of Nursing. Research Brief Volume 62: 2013 RN Practice Analysis: Linking the NCLEX-RN Examination to practice: US and Canada. [Internet]. Chicago (IL). 2015 January. [cited 2016 June 22]. Available from: https : //www. ncsb n.org/15_RN_Practice_Analysis_Vol62_web.pdf

[20] College of Nurses of Ontario. NCLEX-RN for exam writers [Internet] Toronto (ON). [cited 2016 June 22]. Available from: http://www. cno.org/en/become-a-nurse/entry-to-pra ctice-examinations/nclex-rn/exam-writers/qas-about -the-nclex-rn-for-exam-writers/ 
[21] College of Nurses of Ontario. Nursing Registration Exams Report 2015. [Internet] Toronto (ON). Revised 2016 April 21[cited 2016 June 22]. Available from: http://www. cno.org/globalassets /2-howweprotectthepublic/statistical-reports/nursi ng-registration-exams-report-20152.pdf

[22] College of Nurses of Ontario. Nursing Registration Exams Report 2016. [Internet]. Toronto (ON). 2017 March. [cited 2017 Mar 22].
Available from: http://www.cno.org/globalassets/2-how weprotectthepublic/statistical-reports/nursing-reg istration-exams-report-2017/6.pdf

[23] McGillis Hall L, Lalonde M, Kashin J. People are failing! Something needs to be done: Canadian students' experience with the NCLEX-RN. Nurse Educ Today. 2016 Nov; 46: 43-49. https: //doi.org/10.1016/j.nedt.2016.08.022 